\title{
Retraction of "Influence of thermophoresis particle deposition and chemical reaction on unsteady non-Darcy MHD mixed convective flow over a porous wedge in the presence of temperature-dependent viscosity" [JMST 27 (5) (2013) 1545-1555] ${ }^{\dagger}$
}

\author{
I. Muhaimin, R. Kandasamy ${ }^{*}$, Azme B. Khamis and Roslan Rozaini \\ Research Centre for Computational Mathematics, FSTPi \\ Universiti Tun Hussein Onn Malaysia Batu Pahat, Johor, Malaysia
}

The article "Influence of thermophoresis particle deposition and chemical reaction on unsteady non-Darcy MHD mixed convective flow over a porous wedge in the presence of temperature-dependent viscosity" (JMST 27 (5) (2013) 1545-1555) is retracted because it contains significant parts self-plagiarizing two other publications: "Impact of thermophoresis particle deposition and chemical reaction on unsteady non-Darcy mixed convective flow over a porous wedge in the presence of temperature-dependent viscosity" (Meccanica 48 (2013)1415-1430), and "Effect of thermophoresis particle deposition and chemical reaction on unsteady MHD non-Darcy mixed convective flow over a porous wedge in the presence of temperaturedependent viscosity" (Nuclear Engineering and Design 261 (2013) 95-106). 